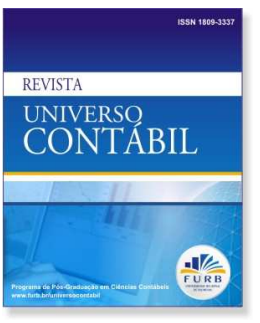

Revista Universo Contábil, ISSN 1809-3337

Blumenau, v. 8, n. 3, p. 24-39, jul./set., 2012

doi: $10.4270 /$ ruc. 2012320

Disponível em www.furb.br/universocontabil

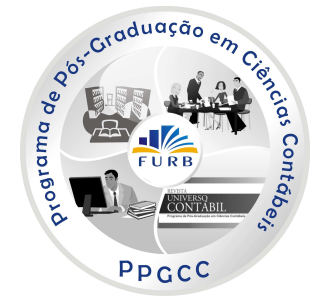

\title{
SER OU NÃO SER INDEPENDENTE? UM ESTUDO EXPLORATÓRIO SOBRE A INDEPENDÊNCIA DAS INSTITUIÇÕES SUPERIORES DE AUDITORIA E O NÍVEL DE TRANSPARÊNCIA FISCAL DOS PAÍSES1
}

\section{TO BE OR NOT TO BE INDEPENDENT? AN EXPLORATORY STUDY ON THE INDEPENDENCE OF SUPREME AUDIT INSTITUTIONS AND THE LEVEL OF COUNTRIES' FISCAL TRANSPARENCY}

\section{¿SER O NO SER INDEPENDIENTE? UN ESTUDIO EXPLORATORIO DE LA INDEPENDENCIA DE LAS ENTIDADES FISCALIZADORAS SUPERIORES Y EL NIVEL DE TRANSPARENCIA FISCAL DE LOS PAÍSES}

\author{
Janilson Antonio da Silva Suzart \\ Doutorando em Controladoria e Contabilidade na FEA/USP \\ Programa de Pós-Graduação em Ciências Contábeis da Faculdade de Economia, \\ Administração e Contabilidade da Universidade de São Paulo \\ Endereço: Av. Professor Luciano Gualberto, 908 - Prédio FEA 3 \\ CEP: 05508-010 - São Paulo/SP - Brasil \\ E-mail: suzart@suzart.cnt.br \\ Telefone: (11) 3091-5920
}

\section{RESUMO}

O objetivo desta pesquisa foi identificar a existência de uma relação entre o nível de independência de uma Instituição Superior de Auditoria e o nível de transparência físcal de um país. A independência de uma instituição auditorial é vista como um fator essencial que pode interferir no desempenho das atividades desta entidade, vez que, está relacionada com a credibilidade que é atribuída a esta instituição. Em razão do objetivo desta pesquisa, foi executada uma análise de conglomerados hierárquica, utilizando o algoritmo de agrupamento de maior distância e a medida de similaridade de distância euclidiana quadrada. A amostra empregada foi composta por dados de 85 países, dentre eles o Brasil. A solução inicial resultou em onze conglomerados. Após a reclassificação, estes foram reorganizados em seis novos grupos. As análises permitiram a constatação de que um bom nível de independência

\footnotetext{
1 Artigo recebido em 30.08.2011. Revisado por pares em 24.12.2011. Reformulado em 21.05.2012. Recomendado para publicação em 23.05.2012 por Ilse Maria Beuren (Editora). Publicado em 30.07.2012. Organização responsável pelo periódico: FURB.
} 
de uma entidade nacional de auditoria está associado com um nível regular ou bom de transparência fiscal de uma nação. A assertiva contrária também foi constatada, ou seja, baixos níveis de independência de uma Instituição Superior de Auditoria estão associados a baixos níveis de transparência fiscal do país. Outra constatação é que, além do nível de transparência fiscal, outras variáveis interferem no nível de independência. A principal limitação desta pesquisa foi a utilização de variáveis relacionadas com a independência de uma Instituição Superior de Auditoria, tendo em vista que houve evidências de que outras variáveis podem impactar a adoção das práticas relacionadas à transparência fiscal.

Palavras-chave: Instituição Superior de Auditoria. Independência. Transparência fiscal.

\section{ABSTRACT}

The aim of this study was to identify the existence of a relationship between the level of independence of a Supreme Audit Institution and the level of fiscal transparency of a country. The independence of an audit institution is seen as an essential factor that can affect the performance of activities of this entity, since it is related to the credibility that is assigned to this institution. Considering the objective of this research, there was performed an analysis hierarchical cluster using the clustering algorithm for greater distance and similarity measure of square Euclidean distance. The sample used was composed of data from 85 countries, including Brazil. The initial solution resulted in eleven clusters. After reclassification, those were reorganized into six new groups. The analysis led to the finding that a level of independence of a national audit is associated with a regular or good level of fiscal transparency of a country. The contrary assertion was also observed, i.e., low levels of independence of a Supreme Audit Institution are associated with low levels of fiscal transparency of the country. Another finding is that, besides the level of fiscal transparency, other variables affect the level of independence. The main limitation of this study was the use of variables related to the independence of a Supreme Audit Institution, given that there were evidences that other variables can impact the adoption of practices related to fiscal transparency.

Keywords: Supreme Audit Institution. Independence. Fiscal transparency.

\section{RESUMEN}

El objetivo de este estudio fue identificar la existencia de una relación entre el nivel de independencia de una Entidad Fiscalizadora Superior y el nivel de transparencia fiscal de un país. La independencia de una institución auditorial es visto como un factor esencial que puede interferir en el desempeño de las actividades de esta entidad, ya que está relacionado con la credibilidad que se le asigna a esta institución. Debido al objetivo de esta investigación se llevó a cabo un análisis de agrupamiento jerárquico utilizando el algoritmo de agrupamiento para una mayor distancia y la medida de similitud de la distancia euclídea cuadrada. La muestra utilizada estaba compuesta por los datos de 85 países, incluyendo Brasil. La solución inicial resultó en once grupos. Después de la reclasificación, estos se han reorganizado en seis nuevos grupos. El análisis permite la observación de que un buen nivel de independencia de una auditoría nacional se asocia con un nivel regular o bueno de transparencia fiscal de una nación. La afirmación contraria también se observó, es decir, los bajos niveles de independencia de una Entidad Fiscalizadora Superior están asociados con bajos niveles de transparencia fiscal en el país. Otra conclusión es que, más allá del nivel de transparencia fiscal, otras variables afectan el nivel de independencia. La principal limitación de este estudio fue el uso de variables relacionadas con la independencia de una 
Entidad Fiscalizadora Superior, pues había evidencia de que otras variables pueden influir en la adopción de prácticas relacionadas con la transparencia fiscal.

Palabras clave: Entidad Fiscalizadora Superior. La independencia. La transparencia fiscal.

\section{INTRODUÇÃO}

A Carta Magna brasileira (BRASIL, 1988) estabelece que qualquer pessoa, física ou jurídica, que utilize ou que seja responsável por recursos públicos federais, tem o dever de prestar contas da gestão destes recursos. A Instituição Superior de Auditoria (ISA) brasileira, o Tribunal de Contas da União (TCU), é a entidade responsável por auxiliar o Poder Legislativo na fiscalização do uso dos recursos públicos pertencentes à União.

Entretanto, nos últimos anos, em especial a partir de 2008, a atuação desta entidade tem sido alvo de críticas, especialmente, por parte do Poder Executivo, responsável pela gestão da maior parcela dos recursos federais. Ao TCU tem sido atribuída a responsabilidade pelo atraso na execução de gastos públicos, principalmente, aos relacionados com investimentos e inversões financeiras.

Em função disto têm surgido algumas propostas, feitas por integrantes dos Poderes Executivo e Legislativo, visando restringir a atuação e o poder desta entidade. Por outro lado, técnicos e estudiosos descrevem que tais intervenções afetariam o nível de independência daquela instituição, anulando ou diminuindo a efetividade das ações de fiscalização implementadas por ela.

Os organismos internacionais destacam que a independência é uma das características essenciais para que uma ISA desempenhe corretamente as suas funções. O Fundo Monetário Internacional (FMI), por exemplo, sugere que os relatórios financeiros governamentais sejam examinados por auditores independentes (FMI, 1999). A sua vez, a Organização para a Cooperação e Desenvolvimento Econômico (OCDE) propõe que, anualmente, os gestores públicos elaborem relatórios de final de exercício (prestação de contas) e que estes devam ser auditados pela ISA (OCDE, 2002).

A Organização Internacional de Entidades Fiscalizadoras Superiores (INTOSAI, em inglês), órgão central que congrega as ISAs, atribui que a independência de uma ISA é condição indispensável para que esta entidade possa certificar a regularidade da gestão dos recursos públicos (INTOSAI, 1977).

O correto desempenho das atividades de uma ISA pode estimular a Administração Pública a realizar práticas que permitam o aumento no nível de transparência fiscal de um país, isto é, os gestores buscariam evidenciar, mais amplamente, informações sobre a sua gestão dos recursos públicos. Em razão disto, nota-se que se a independência de uma entidade auditorial afeta o seu desempenho e este o nível de transparência, então o nível de independência de uma ISA poderia impactar o nível de transparência fiscal de um país.

Diante deste contexto, surge a questão norteadora da presente pesquisa: Até que ponto o nível de independência de uma ISA impacta o nível de transparência fiscal de um país? Na busca pela solução da questão anteriormente descrita, este trabalho apresenta como objetivo principal a identificação da possível relação existente entre o nível de independência de uma ISA e o nível de transparência fiscal de um país.

Os objetivos secundários da presente pesquisa são os seguintes: a) descrever as principais características atribuídas às Instituições Superiores de Auditoria; b) demonstrar os níveis de independência das instituições auditoriais estudadas, ressaltando os pontos fortes e fracos; c) estudar as possíveis relações existentes entre as variáveis estudadas, que tratam do nível de independência das ISAs. 


\section{PLATAFORMA TEÓRICA}

\subsection{As Instituições Superiores de Auditoria}

As Instituições Superiores de Auditoria, também conhecidas como Entidades Superiores de Fiscalização, representam, de acordo com Leeuwen (2004, p. 93), as maiores entidades nacionais de auditoria pública, sendo responsáveis por fiscalizar a regularidade do uso do erário, assim como, a economia, a eficiência e a eficácia das políticas públicas.

Segundo Santiso (2006, p. 98), as ISAs são entidades estatais encarregadas de supervisionar o uso de recursos públicos, visando garantir a confiabilidade das demonstrações financeiras e a veracidade das demais informações evidenciadas pelas entidades estatais auditadas.

Considerando que a auditoria, segundo a INTOSAI (1977), “[...] não é um fim em si mesma, e sim um elemento indispensável de um sistema regulatório [...]", as ISAs são entidades integrantes deste sistema, cujo objetivo é revelar desvios e violações, bem como, propor medidas corretivas. Através das atividades desempenhadas pelas ISAs, os cidadãos podem ter acesso às informações, qualitativas e quantitativas, da utilização dos recursos públicos.

Dye e Stapenhurst (1998, p. 5-6) afirmam que, quanto ao modelo organizacional, existem três modelos principais de ISAs:

a) Tribunal de Contas - modelo original da França, os Tribunais de Contas possuem um número específico de magistrados, que possuem independência e são responsáveis por apreciar e julgar as contas prestadas pelos agentes públicos, em especial a observação da conformidade com a lei dos atos praticados. É o modelo predominante na Europa e na América Latina, estando presente em alguns países africanos.

b) Escritório Geral de Auditoria - também denominado Modelo de Westminster, este modelo apresenta um Auditor Geral, responsável por apresentar os relatórios das auditorias realizadas ao Parlamento. O escritório é um órgão colegiado, sendo um modelo comum nos países anglo-saxões. As auditorias dão menos ênfase ao exame da legalidade, sendo, entretanto, mais sofisticadas do que as do modelo anterior.

c) Comitê de Auditoria - é um modelo semelhante ao Modelo de Westminster, com Auditor Geral e uma diretoria colegiada. É o modelo predominante na Ásia.

Independente da forma estrutural e do nível de independência das ISAs, a literatura analisada (DYE; STAPENHURST, 1998; LEEUWEN, 2004; NIKODEM, 2004; SUZUKI, 2004; CLARK; MARTINIS; KRAMBIA-KAPARDIS, 2007) aponta que tais entidades, de um modo geral, desempenham os seguintes papéis:

a) detectar violações da legislação, assim como, fraudes e abusos;

b) verificar a exatidão e a adequação dos relatórios financeiros;

c) verificar a adequação dos programas públicos em comparação com os objetivos declarados nos documentos orçamentários;

d) relatar ao parlamento e aos cidadãos o estado das contas e da execução das atividades públicas;

e) garantir que a prática de prestar contas seja contínua e regular entre os gestores públicos;

f) promover a governança corporativa em auxílio à gestão pública;

g) estimular a transparência fiscal, permitindo o livre fluxo de informações das movimentações feitas no erário;

h) avaliar o cumprimento, a nível nacional, dos compromissos e obrigações internacionais.

Em relação ao desempenho das ISAs, o Banco Mundial (WORLD BANK, 2004, p. 
10-11) descreve que muitos fatores o influenciam. Dentre eles, destacam-se: o ambiente político, as tradições jurídico-administrativas e o engajamento da sociedade civil. Em razão destes fatores, os tipos de auditorias e as características das entidades diferem muito entre os países. Entretanto, ressalta que três características são necessárias para que uma ISA desempenhe bem as suas atividades: "[...] independência do Poder Executivo, objetividade e neutralidade $[\ldots] "$..

A objetividade está relacionada com a execução dos trabalhos com base exclusiva nas evidências obtidas e de acordo com os padrões. A neutralidade, a sua vez, está relacionada com o distanciamento da influência do cenário político de modo a avaliar imparcialmente as ações dos gestores públicos. Na continuação, passa-se a analisar a questão da independência no contexto das ISAs.

\subsection{A independência de uma ISA}

Ser independente daqueles cujas atividades serão examinadas, é uma condição essencial nos trabalhos auditoriais. A ausência de independência de um auditor, fatalmente, estará associada à ausência de credibilidade de seus relatórios.

Em uma ISA, a situação é a idêntica ao relato acima. De acordo com Santiso (2006, p. 98), a independência de uma ISA é uma condição fundamental para reforçar a credibilidade nos demonstrativos financeiros públicos e assegurar a probidade dos gestores, no uso dos recursos públicos.

Sandberg e Larsson (1996, p. 196) exemplificam que a ausência de independência por parte das entidades auditoriais, públicas e privadas, contribuiu para o colapso dos mercados financeiros e mobiliários em muitos países, na década de 1990.

Para uma ISA, a independência propicia a capacidade de exercer julgamentos objetivos sobre as áreas e entidades auditadas, pois, esta característica serve para proteger a instituição de interferências e pressões políticas. Blume e Voigt (2007, p. 9) ressaltam que a independência deve ser ampla, ou seja, a entidade deve ser independente tanto em relação aos auditados, quanto em relação ao destinatário de seus relatórios. Entretanto, a INTOSAI (1977) complementa que, considerando que seria utópico estabelecer uma total independência, vez que as ISAs são entidades integrantes dos Estados, estas entidades devem ter, pelo menos, "[...] independência funcional e organizacional para desempenhar suas tarefas".

Muitos fatores interferem no nível de independência de uma ISA. Dentre eles, a literatura (INTOSAI, 1977; SANDBERG; LARSSON, 1996; DYE; STAPENHURST, 1998; SANTISO, 2006; BLUME; CLARK; MARTINIS; KRAMBIA-KAPARDIS, 2007; GOOLSARRAN, 2007; VOIGT, 2007; ZYL; RAMKUMAR; RENZIO, 2009) destacam os seguintes:

a) Independência institucional consagrada em lei - quando a independência de uma ISA está consagrada na constituição nacional e/ou em leis infraconstitucionais, esta instituição garante uma proteção jurídica. Qualquer ato, que cause interferência em suas atividades, poderá ser questionado junto às autoridades judiciais do país;

b) Independência de seus membros - as formas de escolha dos membros da direção da instituição, assim como, o ingresso e o desligamento dos demais membros interferem na independência das ISAs. Desta forma, a independência da entidade está atrelada a existência de regras claras que garantam a independência de seus membros;

c) Autonomia funcional e administrativa - o nível de independência é afetado pelo nível de liberdade que a entidade auditorial possui para determinar as condições e os tipos de trabalhos que serão realizados;

d) Autonomia financeira - uma ISA necessita de uma fonte de financiamento 
adequada, que permita a execução de todas as suas atividades. A dependência financeira, além de interferir nestas atividades, poderá afetar a autonomia funcional e administrativa desta entidade;

e) Autoridade - a independência de uma entidade auditorial está associada com a presença de autoridade para solicitar e obter todas as informações consideradas necessárias, assim como, para convencer ou exigir que os gestores públicos atendam a suas recomendações. A ausência desta capacidade afeta $o$ desenvolvimento dos trabalhos e, consequentemente, o nível de independência de uma ISA.

Alguns outros fatores, descritos a seguir, apresentam a capacidade interferir na independência de uma instituição auditorial:

a) política remuneratória dos membros da instituição (BLUME; VOIGT, 2007, p. 9);

b) bom funcionamento das instituições jurídicas nacionais (CLARK; MARTINIS; KAMBRIA-KAPARDIS, 2007, p. 43);

c) elaboração de relatórios diretamente para o Poder Legislativo (CLARK; MARTINIS; KAMBRIA-KAPARDIS, 2007, p. 43);

d) poder estatal que detém a prerrogativa de nomear o chefe da ISA (CLARK; MARTINIS; KAMBRIA-KAPARDIS, 2007, p. 43);

e) experiência e grau de instrução dos membros da entidade (DYE; STAPENHURST, 1998, p. 7).

Por fim, destaca-se que o nível de independência de uma ISA está relacionado com a credibilidade de suas atividades. Entretanto, a independência não deve funcionar como um fator de isolamento entre a instituição e os demais entes estatais.

Santiso (2006, p. 98) afirma que uma ISA necessita desenvolver relações com as demais entidades públicas, visando o aperfeiçoamento de suas atividades. Zyl, Ramkumar e Renzio (2009, p. 21) complementam que o isolamento de uma ISA, como justificativa para preservar a sua independência, torna a sua atuação contra-produtiva.

No próximo item serão apresentados alguns dos estudos anteriores, que envolveram a temática desta pesquisa.

\subsection{Pesquisas Antecedentes}

Este item é destinado à apresentação de pesquisas anteriores que versaram, direta ou indiretamente, sobre a temática abordada na presente pesquisa. Busca-se destacar o contexto e os achados das pesquisas citadas.

O primeiro artigo analisado, de Santiso (2006), objetivou avaliar a eficácia das ISAs, pertencentes a países considerados economicamente emergentes e que funcionavam como órgão consultivo do Poder Legislativo. Para isto, foram coletados dados sobre dez países, a maioria latino-americana, e suas instituições auditoriais.

Dentre outras conclusões, o autor descreve que nos moldes utilizados, o nível de independência de uma ISA é mais bem representado por uma variável do tipo contínua, ao invés de uma do tipo dicotômica (ausência ou presença de independência), conforme foi utilizado em sua pesquisa. A justificativa seria que a independência não seria um fim em si mesma, funcionando como uma garantia de que a instituição seria imparcial e credível.

Este autor, ainda, relata outra constatação da pesquisa, a qual ele denominou como o paradoxo da independência: Apesar de ser independente, uma ISA precisa se relacionar funcionalmente com outras instituições responsáveis, em algum grau, pela fiscalização da gestão pública.

O segundo artigo analisado, de Blume e Voigt (2007), buscou avaliar os efeitos econômicos provenientes das atuações das ISAs. Foram utilizados dados de 40 países, obtidos junto à INTOSAI, à OCDE e ao Banco Mundial, sendo analisados os impactos em relação às 
seguintes variáveis: política fiscal, eficácia do governo e produtividade.

Em relação à independência das ISAs, estes autores constataram que em mais da metade da amostra analisada a independência é estabelecida constitucionalmente. Em menos da metade destes países, ela é consagrada apenas na legislação infraconstitucional.

O terceiro artigo em análise, Morin (2007), trata-se de um estudo de caso sobre a ISA francesa. A autora procurou identificar de que maneira a instituição francesa buscava integrar suas atividades, confrontando-as com o estabelecido pela INTOSAI, na Declaração de Lima (1977).

Para a consecução deste estudo de caso, a autora entrevistou 40 magistrados do Tribunal de Contas francês, tendo, inclusive, convivido com seus componentes, por seis meses nas dependências daquela ISA.

Dentre as principais constatações relatadas pela autora e que se referem à questão da independência, destacou-se o baixo nível de independência da ISA, em relação ao Poder Executivo francês.

O quarto trabalho, dos autores Clark, Martinis e Krambia-Kapardis (2007), objetivou examinar, na legislação de países membros e da própria Comunidade Europeia, o relacionamento das ISAs com o Poder Legislativo e a independência destas instituições, em relação ao Poder Executivo. A amostra estudada compreendeu 25 ISAs nacionais, além, da ISA da União Europeia.

As análises foram divididas em dois grupos: independência dos auditores e independência da ISA. Em relação à independência dos auditores, somente sete países consagraram esta característica em seus normativos. Este percentual melhorou em relação à ISA, sendo que dezenove países e a União Europeia estabelecem cláusulas que garantem a independência da entidade auditorial, em suas legislações.

Estes autores descreveram que a independência de uma ISA é requisito primordial para a qualidade das auditorias realizadas e que esta independência aumenta a responsabilidade dos gestores públicos auditados.

O último artigo analisado é um estudo de caso sobre a ISA mexicana, desenvolvido por Aragón (2009). O objetivo deste estudo foi identificar as percepções da sociedade mexicana, em respeito a sua entidade auditorial.

Com relação à independência da ISA, a maioria dos componentes, que compuseram a amostra, considera que a independência é um aspecto importante, pois, ela estaria associada à confiabilidade de regular uso de recursos públicos, assim como, seria responsável pela promoção da transparência desta utilização.

No próximo item é apresentada a discussão sobre as ISAs como propulsoras da transparência fiscal.

\subsection{As Instituições Superiores de Auditoria e a transparência fiscal}

A transparência fiscal se refere às atividades desempenhadas pelos governos com o objetivo de tornar públicas as informações sobre a utilização dos recursos públicos.

Kopits e Craig (1998, p. 1) definem transparência fiscal como sendo o processo de abertura para o público em geral, realizado pelo governo, de informações sobre estrutura, funções, política fiscal, contas, intenções e projeções governamentais. Complementam que estas informações devem ser confiáveis, claras, completas e oportunas, abrangendo todas as ações executadas e propiciando que os cidadãos possam compará-las e avaliá-las.

Nota-se que, a transparência fiscal compreende ações que visam reduzir a assimetria informacional entre os gestores públicos e os cidadãos, através da evidenciação das atividades dos gestores públicos. Entretanto, a sociedade precisa verificar a integridade das informações repassadas pelos gestores, a fim de evitar comportamentos oportunísticos destes gestores. A sociedade pode efetuar isto através do monitoramento dos gestores, ou seja, pode controlar as 
escolhas dos gestores públicos mediante instrumentos que tornam mais transparentes as suas ações. Um exemplo deste monitoramento é o trabalho efetuado pelas instituições auditoriais.

O FMI (2001, p. 9) apresenta os seguintes requisitos como fundamentais para a transparência fiscal:

a) definição clara de funções e responsabilidades - este requisito se relaciona com a existência de uma estrutura e um conjunto das funções governamentais, assim como, da divulgação das relações, internas e externas, do governo;

b) acesso público à informação - os relatórios fiscais devem evidenciar todas as atividades orçamentárias e extraorçamentárias do governo, incluindo dívidas, passivos eventuais e renúncias fiscais;

c) abertura na preparação, execução e prestação de contas no orçamento - existe a necessidade de divulgação dos documentos orçamentários, aqui compreendidos desde aqueles que auxiliam na elaboração do orçamento, passando pelo próprio orçamento até o processo de prestação de contas;

d) garantias de integridade - as informações orçamentárias devem ser completas, verificáveis, tempestivas e precisas, em especial, as normas contábeis e os resultados das auditorias realizadas.

Mais uma vez, percebe-se que garantir a integridade das informações divulgadas pela Administração Pública é uma atividade essencial para promover a transparência fiscal.

As ISAs desempenham um papel importante na validação das informações evidenciadas pelos gestores públicos. Conforme foi descrito no item anterior, quando uma instituição de auditoria é independente, política e financeiramente, ela auxilia a sociedade ao atestar e divulgar a real situação da parcela analisada do patrimônio público. Além de evidenciar o nível de integridade das informações repassadas pelos gestores públicos, estas instituições demonstram e sancionam as más práticas realizadas pelos agentes públicos.

Em uma análise sobre os aspectos teóricos e as práticas de diversos países, sob a ótica da transparência fiscal, Premchand (2002, p. 141) afirma que a realização de auditorias reforça a confiança que os cidadãos têm sobre os gestores públicos. Entretanto, na década de 1990, este autor destaca que o desempenho global das ISAs deixou a desejar. Os principais motivos para este desempenho foram:

a) ausência de independência para analisar os gastos realizados pelos gestores públicos;

b) escopo limitado apenas nos resultados financeiros do ente estatal analisado;

c) limitação ou desatualização dos normativos que designavam a competência das ISAs.

Apesar do desempenho anteriormente relatado, este autor ressalta que na década analisada, houve um grande esforço por parte dos países analisados, visando o estabelecimento de sistemas auditoriais.

\section{METODOLOGIA DA PESQUISA}

A presente pesquisa se caracteriza, quanto aos fins, como sendo uma pesquisa de natureza exploratória, pois, conforme aponta Piovesan e Temporini (1995, p. 322), “[...] tem por objetivo conhecer a variável de estudo tal como se apresenta, seu significado e o contexto onde ela se insere". Quanto ao tipo, a pesquisa pode ser classificada como empírico-analítica, uma vez que buscou identificar a existência de relações entre as variáveis analisadas.

A base de dados utilizada é originada do questionário Open Budget Initiative 2008, um programa que busca demonstrar informações sobre os processos orçamentários nacionais (INTERNATIONAL BUDGET PARTNERSHIP, 2010). A amostra foi composta por 85 países: Afeganistão, África do Sul, Albânia, Alemanha, Angola, Arábia Saudita, Argélia, Argentina, Azerbaijão, Bangladesh, Bolívia, Bósnia-Herzegovina, Botsuana, Brasil, Bulgária, 
Burquina Fasso, Camarões, Camboja, Cazaquistão, Chade, China, Colômbia, Congo, Coreia do Sul, Costa Rica, Croácia, Egito, El Salvador, Equador, Eslovênia, Estados Unidos, Fiji, Filipinas, França, Gana, Geórgia, Guatemala, Guiné Equatorial, Honduras, Iêmen, Índia, Indonésia, Jordânia, Líbano, Libéria, Macedônia, Malásia, Malauí, Marrocos, México, Mongólia, Namíbia, Nepal, Nicarágua, Níger, Nigéria, Noruega, Nova Zelândia, Papua Nova Guiné, Paquistão, Peru, Polônia, Quênia, Quirguistão, Reino Unido, República Dominicana, República Tcheca, Romênia, Ruanda, Rússia, São Tomé e Príncipe, Senegal, Sérvia, Sri Lanka, Sudão, Suécia, Tailândia, Tanzânia, Trinidad e Tobago, Turquia, Ucrânia, Uganda, Venezuela, Vietnã e Zâmbia.

Os dados da supracitada base se referem ao exercício de 2008 e anteriores. O ano de referência dos dados é o de 2008. Alguns documentos (tais como, normativos) podem ter sido emitidos em anos anteriores, entretanto foram aplicáveis ao exercício de 2008.

Para analisar a existência desta relação, foi escolhida a técnica estatística de análise de conglomerados hierárquica, objetivando reunir os países parecidos em grupos de acordo com as características da independência da ISA e do nível de transparência fiscal do país.

As três primeiras variáveis, todas relacionadas com o nível de independência de uma ISA, foram os seguintes:

a) restrições para a destituição do chefe da entidade (ides);

b) discricionariedade para definir e realizar auditorias (idis);

c) autonomia financeira (ifin).

Os valores destas variáveis foram obtidos dos valores atribuídos, respectivamente, aos itens 114, 116 e 117 do questionário Open Budget Initiative 2008.

A última variável ( $t$ fis) utilizada para a formação de grupos, diz respeito ao nível de transparência fiscal. Para isto, esta variável assumiu os valores do Open Budget Index.

Os valores de todas as variáveis foram transformados para uma escala centesimal, isto é, estão apresentados em um intervalo entre zero a um. Para auxiliar as análises, optou-se, após a formação dos grupos, pela construção de intervalos para cada uma das variáveis, aos quais foram atribuídos qualificativos, conforme demonstrado no Quadro 1.

\begin{tabular}{|c|c|c|}
\hline Nível & Limite Inferior & Limite Superior \\
\hline Baixo & Menor valor da variável & Média da variável \\
\hline Regular & Média da variável & $\begin{array}{c}\text { Valor equidistante entre a média e o valor } \\
\text { máximo da variável }\end{array}$ \\
\hline Bom & $\begin{array}{c}\text { Valor equidistante entre a média e o valor } \\
\text { máximo da variável }\end{array}$ & Valor máximo \\
\hline
\end{tabular}

Quadro 1 - Intervalos de classificação

Após a recodificação e a organização das variáveis, os dados foram analisados mediante uso do aplicativo estatístico SPSS, versão 16.0. A análise de conglomerados hierárquica foi executada com as seguintes opções: algoritmo de agrupamento maior distância (furthest neighbor) e medida de similaridade distância euclidiana quadrada (squared Euclidean distance).

\section{ANÁLISE DOS RESULTADOS}

A primeira etapa realizada foi analisar descritivamente as variáveis estudadas, visando à determinação de alguns valores estatísticos, apresentados na Tabela 1 e que auxiliaram na construção dos intervalos de classificação utilizados na presente pesquisa. 
Tabela 1 - Estatística descritiva das variáveis estudadas

\begin{tabular}{c|c|c|c|c}
\hline Variável & Mínimo & Média & Máximo & Desvio-padrão \\
\hline tfis & 0,000 & 0,394 & 0,880 & 0,253 \\
ides & 0,000 & 0,706 & 1,000 & 0,458 \\
idis & 0,000 & 0,800 & 1,000 & 0,310 \\
ifin & 0,000 & 0,498 & 1,000 & 0,401 \\
\hline
\end{tabular}

Fonte: Dados da pesquisa.

$\mathrm{Na}$ Tabela 2, são apresentados os intervalos de classificação destas variáveis, conforme critério demonstrado na metodologia do estudo.

Tabela 2 - Intervalos de classificação das variáveis estudadas

\begin{tabular}{|c|c|c|c|c|}
\hline \multirow{2}{*}{ Nível } & \multicolumn{4}{|c|}{ Variável } \\
\hline & tfis & ides & idis & Ifin \\
\hline Baixo & $0,00-0,39$ & \begin{tabular}{l|l}
0,00 & $-0,71$
\end{tabular} & \begin{tabular}{l|l}
0,00 & $-0,80$
\end{tabular} & $0,00-0,50$ \\
\hline Regular & $0,39 \longmapsto 0,64$ & $0,71 \vdash 0,85$ & $0,80 \vdash 0,90$ & $0,50 \vdash 0,75$ \\
\hline Bom & $0,64 \longmapsto \mid-10,88$ & $0,85 \longmapsto \mid$ & 1,00 & $0,75 \longmapsto 1,00$ \\
\hline
\end{tabular}

Fonte: Dados da pesquisa.

A etapa seguinte consistiu na determinação da quantidade de conglomerados, de maneira a aperfeiçoar a análise. Maroco (2007, p. 438-439) sugere como critério de determinação desta quantidade, uma análise gráfica através de um diagrama de dispersão formado pelas seguintes variáveis: número de conglomerados, distância entre conglomerados e o critério do $\mathrm{R}^{2}$. A quantidade ideal de conglomerados é determinada pela intersecção entre os gráficos resultantes. O diagrama resultante é apresentado no Gráfico 1.

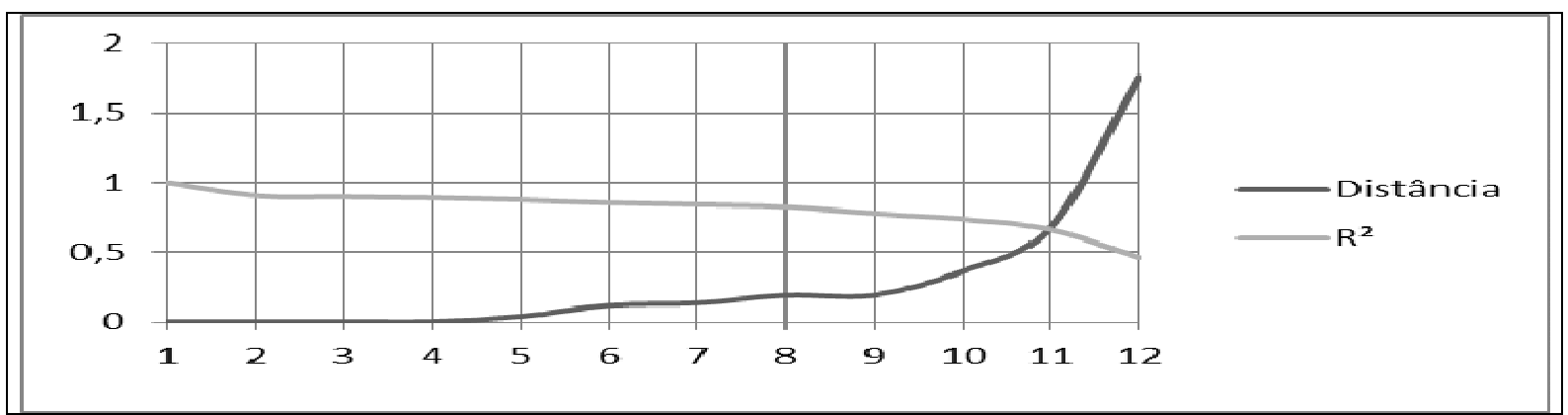

Gráfico 1 - Diagrama de dispersão para determinação do número de conglomerados Fonte: Dados da pesquisa.

$\mathrm{Na}$ análise do Gráfico 1, verificou-se que a quantidade ideal de conglomerados era igual a onze. Após este procedimento, foi realizada uma análise de conglomerados hierárquica, de acordo com os critérios descritos no item anterior. No Gráfico 2, é apresentado o dendograma resultante desta técnica. 


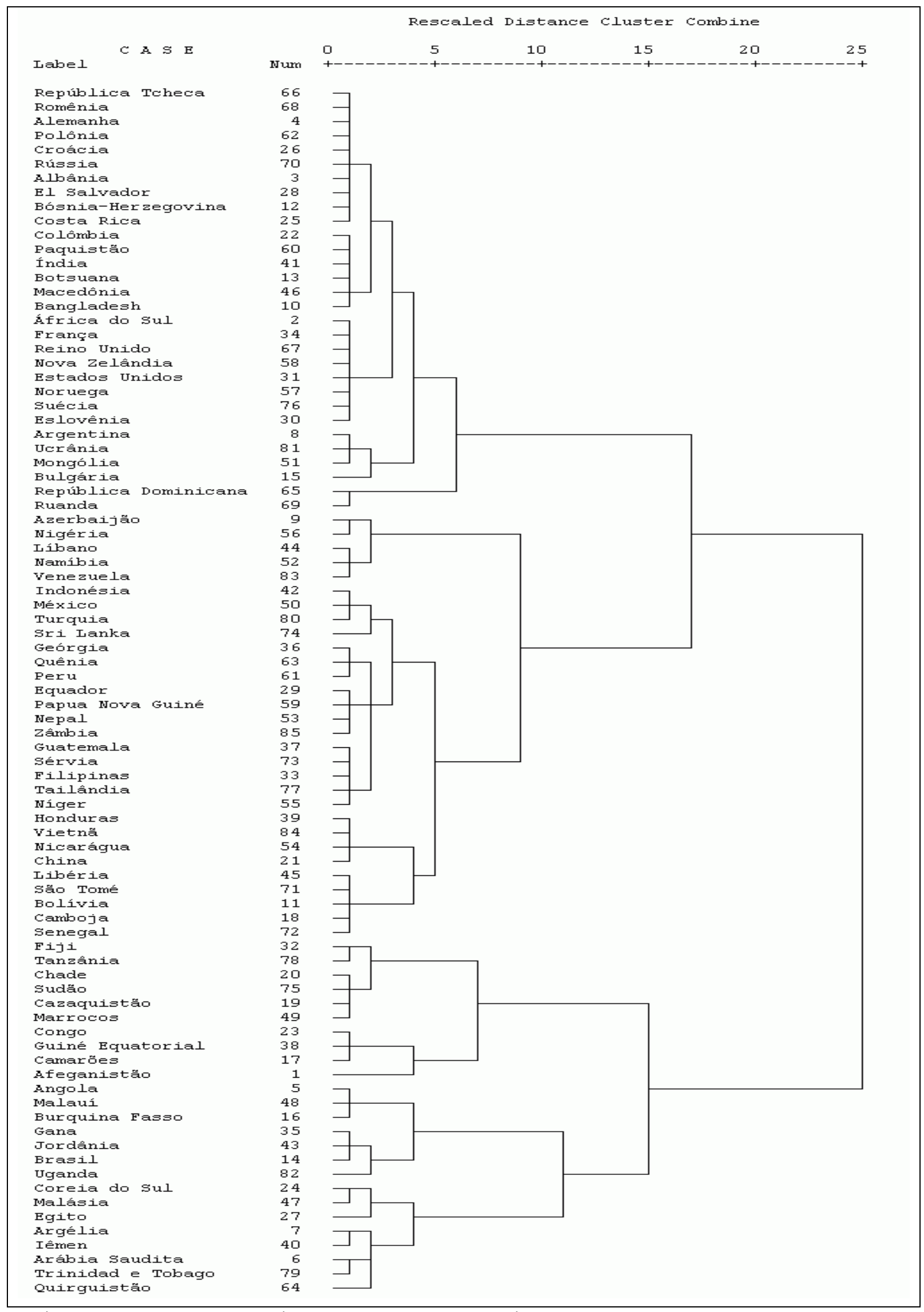

Gráfico 2 - Dendograma da análise de conglomerados hierárquica

Fonte: Dados da pesquisa. 
O dendograma funciona como uma espécie de resumo gráfico da formação dos agrupamentos. Para melhor identificação destes agrupamentos, no Quadro 2 é exibida a composição de cada um deles.

\begin{tabular}{|c|l|c|}
\hline Agrupamento & \multicolumn{1}{|c|}{ Países } & Quantidade \\
\hline A & Afeganistão, Camarões, Congo e Guiné Equatorial. & 4 \\
\hline B & $\begin{array}{l}\text { África do Sul, Albânia, Alemanha, Bangladesh, Bósnia-Herzegovina, } \\
\text { Botsuana, Colômbia, Costa Rica, Croácia, El Salvador, Eslovênia, Estados } \\
\text { Unidos, França, Îndia, Macedônia, Noruega, Nova Zelândia, Paquistão, } \\
\text { Polônia, Reino Unido, República Tcheca, Romênia, Rússia e Suécia. }\end{array}$ & 24 \\
\hline C & Angola, Brasil, Burquina Fasso, Gana, Jordânia, Malaú e Uganda. & 7 \\
\hline D & $\begin{array}{l}\text { Arábia Saudita, Argélia, Coreia do Sul, Egito, Iêmen, Malásia, Quirguistão } \\
\text { e Trinidad e Tobago. }\end{array}$ & 8 \\
\hline E & Argentina, Bulgária, Mongólia e Ucrânia. & 4 \\
\hline F & Azerbaijão, Líbano, Namíbia, Nigéria e Venezuela. & 5 \\
\hline G & Bolívia, Camboja, Libéria, São Tomé e Senegal. & 5 \\
\hline I & Cazaquistão, Chade, Fiji, Marrocos, Sudão e Tanzânia. & 4 \\
\hline J & China, Honduras, Nicarágua e Vietnã. & 16 \\
\hline K & $\begin{array}{l}\text { Equador, Filipinas, Geórgia, Guatemala, Indonésia, México, Nepal, Níger, } \\
\text { Papua Nova Guiné, Peru, Quênia, Sérvia, Sri Lanka, Tailândia, Turquia e } \\
\text { Zâmbia. }\end{array}$ & 2 \\
\hline
\end{tabular}

Quadro 2- Composição dos agrupamentos

Fonte: Dados da pesquisa.

O maior conglomerado é composto por 24 países e o segundo maior, por dezesseis países. O menor conglomerado possui apenas dois países.

Visando auxiliar a análise, na Tabela 3 apresentam-se as médias de cada grupo, assim como, a classificação de acordo com os intervalos definidos na Tabela 2.

Tabela 3 - Médias e nível de classificação das variáveis por conglomerados

\begin{tabular}{c|c|c|c|c|c|c|c|c}
\hline \multirow{2}{*}{ Conglomerado } & \multicolumn{9}{|c|}{ Variável } \\
\cline { 2 - 9 } & \multicolumn{2}{|c|}{ tfis } & \multicolumn{2}{c|}{ ides } & \multicolumn{2}{c}{ idis } & \multicolumn{2}{c}{ ifin } \\
\cline { 2 - 9 } & Média & Classif. & Média & Classif. & Média & Classif. & Média & Classif. \\
\hline A & 0,03 & Baixo & 0,00 & Baixo & 0,00 & Baixo & 0,25 & Baixo \\
B & 0,64 & Regular & 1,00 & Bom & 1,00 & Bom & 0,92 & Bom \\
C & 0,39 & Baixo & 0,00 & Baixo & 0,95 & Bom & 0,09 & Baixo \\
D & 0,24 & Baixo & 0,00 & Baixo & 0,88 & Regular & 0,75 & Bom \\
E & 0,51 & Regular & 1,00 & Bom & 0,59 & Baixo & 1,00 & Bom \\
F & 0,34 & Baixo & 1,00 & Bom & 0,20 & Baixo & 0,07 & Baixo \\
G & 0,04 & Baixo & 1,00 & Bom & 1,00 & Bom & 0,20 & Baixo \\
H & 0,19 & Baixo & 0,00 & Baixo & 0,44 & Baixo & 0,00 & Baixo \\
I & 0,13 & Baixo & 1,00 & Bom & 0,67 & Baixo & 0,42 & Baixo \\
J & 0,48 & Regular & 1,00 & Bom & 0,92 & Bom & 0,23 & Baixo \\
K & 0,06 & Baixo & 1,00 & Bom & 1,00 & Bom & 1,00 & Bom \\
\hline
\end{tabular}

Fonte: Dados da pesquisa.

As primeiras constatações estão relacionadas com os conglomerados "B" e " $\mathrm{K}$ ". No conglomerado "B", com 24 países, os bons níveis das variáveis relacionadas com a independência da ISA estão associados com regulares ou bons níveis de transparência fiscal. Em sentido contrário, no conglomerado " $K$ ", que possui apenas dois países, apesar destes apresentarem bons níveis das variáveis relacionadas com a independência da ISA, os países possuem baixo nível de transparência fiscal.

Observa-se que um bom nível de independência de uma ISA, nas três variáveis analisadas, pode estar associado com um regular ou bom nível de transparência fiscal, conforme foi comprovado em $84,6 \%$ dos países dos conglomerados "B" e " $\mathrm{K}$ ". 
No percentual restante, em especial, nos países do conglomerado "K", percebe-se que apenas bons níveis nas variáveis relacionadas com a independência de uma ISA não garantem um bom nível de transparência fiscal. Desta forma, pode-se afirmar que outras variáveis podem afetar o nível de transparência fiscal de um país, variáveis estas que não se relacionam, necessariamente, com o nível de independência de uma instituição auditorial.

Outra constatação é que, individualmente, nenhuma das variáveis relacionadas com o nível de independência pode afetar, significativamente, o nível de transparência fiscal.

Nos conglomerados " $\mathrm{A}$ " e " $\mathrm{H}$ ", com quatro e seis países, respectivamente, os baixos níveis das variáveis relacionadas com a independência da ISA estão associados a baixos níveis de transparência fiscal. Destaca-se que, em todos estes dez países, o chefe da ISA não possui garantias que o protejam de ser destituído, tais como, uma consulta prévia ao Poder Legislativo ou ao Judiciário.

As entidades auditoriais dos países pertencentes ao conglomerado "A" não possuem discricionariedade para definir quais auditorias serão realizadas. No grupo "H", as ISAs não possuem autonomia financeira, o que limita o desempenho das atividades destas instituições.

Considerando a variável que trata da existência de restrições para destituição do chefe das ISAs, observa-se que nos países dos conglomerados "B", "E", "F", "G", "I", "J" e "K" estão estabelecidas condições que garantem que o Poder Executivo não pode, sozinho, destituir os chefes destas entidades ou que não permitem a destituição sumária destes chefes.

Em se tratando da variável sobre a discricionariedade para definir e realizar auditorias, na maioria dos países dos conglomerados "B", "C", "D", "G", "J" e "K", 87,1\% dos casos, as ISAs têm total autonomia para decidir que auditorias serão realizadas.

A sua vez, em relação a terceira variável, que versa sobre a autonomia financeira da ISA, na maioria dos países dos grupos "B", "D", "E" e "K", 68,4\% do total, as instituições auditoriais possuem adequado financiamento para desempenharem suas atividades. Os orçamentos destas instituições não são determinados pelo Poder Executivo.

Os conglomerados "A" e "H" apresentam baixo nível de independência da ISAs, em relação às garantias para destituição do chefe e à autonomia funcional e administrativa. Nestes países, os baixos níveis das variáveis ides e idis estão associados ao baixo nível de transparência fiscal.

Em relação às variáveis ides e ifin, nos grupos "A", "C" e "H", que possuem um total de dezessete países, baixos níveis destas variáveis estão associadas a baixos níveis de transparência fiscal, também.

No conglomerado "E", os bons níveis das variáveis relativas às garantias do chefe da ISA e à autonomia financeira, dos países que o compõe, estão associados a um regular nível de transparência fiscal. Esta situação se repete com os países do grupo "J", só que em relação às variáveis ides e idis.

Em sentido contrário, no conglomerado "G", apesar dos bons níveis das variáveis ides e idis, os países possuem baixo nível de transparência fiscal. Esta constatação reforça outra, feita anteriormente, sobre a existência de outras variáveis que podem afetar o nível de transparência.

Por fim, após estas constatações, demonstra-se no Quadro 3 uma nova formação de agrupamentos, considerando além das constatações a classificação apresentada na Tabela 3.

Nesta reclassificação, percebe-se que apenas no primeiro grupo “ $\alpha$ ", os países possuem, em média, um nível regular de transparência fiscal que está associado aos bons níveis de pelo menos duas das três variáveis relacionadas com a independência da ISA

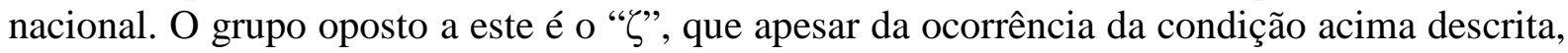
em relação às variáveis atribuídas ao nível de independência, seus países possuem baixo nível de transparência fiscal. 


\begin{tabular}{|c|c|c|c|c|c|c|}
\hline \multirow{2}{*}{$\begin{array}{l}\text { Novo } \\
\text { grupo }\end{array}$} & \multirow{2}{*}{$\begin{array}{c}\text { Conglomerados } \\
\text { originais }\end{array}$} & \multirow{2}{*}{$\begin{array}{c}\text { Número de } \\
\text { países }\end{array}$} & \multicolumn{4}{|c|}{ Variável } \\
\cline { 4 - 6 } & & & tfis & ides & idis & ifin \\
\cline { 4 - 7 } & & Classificação & Classificação & Classificação & Classificação \\
\hline$\alpha$ & "B", "E" e "J" & 44 & Regular & Bom & Baixo ou Bom & Baixo ou Bom \\
$\beta$ & "A"e "H" & 10 & Baixo & Baixo & Baixo & Baixo \\
$\gamma$ & "F"e "I" & 9 & Baixo & Bom & Baixo & Baixo \\
$\delta$ & "C" & 7 & Baixo & Baixo & Bom & Baixo \\
$\varepsilon$ & "D" & 8 & Baixo & Baixo & Regular & Bom \\
$\zeta$ & "G"e "K" & 7 & Baixo & Bom & Bom & Baixo ou Bom \\
\hline
\end{tabular}

Quadro 3 - Formação de novos agrupamentos

Fonte: Dados da pesquisa.

Nos demais grupos, o baixo nível de transparência fiscal está associado, em média, aos baixos ou regulares níveis de duas das variáveis ides, idis e ifin.

\section{CONCLUSÕES}

Estudiosos e organizações mundiais afirmam que, a independência de uma Instituição Superior de Auditoria é uma das condições primordiais para que ela desempenhe bem suas atividades. A esta condição é associada, também, a credibilidade do trabalho realizado pela instituição.

A independência de uma ISA deve ser completa, em relação às demais entidades públicas nacionais. As interferências ou pressões políticas podem reduzir o nível de independência desta instituição.

A literatura especializada destaca que os principais fatores que interferem na independência de uma ISA são: (i) independência institucional consagrada em lei; (ii) independência de seus membros; (iii) autonomia funcional e administrativa; (iv) autonomia financeira; e, (v) autoridade.

Outra assertiva feita pela literatura é que, o desempenho de uma ISA afeta o nível de transparência fiscal de um país e este desempenho é afetado pelo nível de independência da entidade auditorial. Desta forma, o nível de independência da ISA pode impactar o nível de transparência fiscal.

Tendo em consideração este contexto, a presente pesquisa procurou identificar a existência de relação entre o nível de independência de uma ISA e o nível de transparência fiscal de um país. Para isto, foi utilizada a técnica estatística de análise de conglomerados hierárquica em uma amostra composta por 85 países, sendo que os dados originais foram provenientes da base de dados do Open Budget Initiative 2008.

A quantidade ideal de conglomerados, identificado através de um diagrama de dispersão, foi onze. Considerando os grupos iniciais, o menor conglomerado possuía dois países e o maior, 24 países.

Após a organização das médias de cada conglomerado e a reclassificação destes, de acordo com o critério definido na metodologia e o resultado das análises realizadas, obteve-se a formação de seis novos grupos, que sintetizaram as relações constatadas.

Desta forma, foi observado que, na maioria dos casos, quando duas das três variáveis, relacionadas com a independência da ISA, possuem bom nível, o país possui um nível regular ou bom de transparência fiscal. Isto significa dizer que um bom nível de independência de uma ISA está associado a um regular ou bom nível de transparência fiscal de um país.

Em sentido contrário, na maioria dos casos, quando duas daquelas variáveis apresentam baixo nível, o país apresenta um baixo nível de transparência. Da mesma forma que ocorreu na constatação anterior, pode-se afirmar que um baixo nível de independência de uma instituição auditorial está associado a um baixo nível de transparência fiscal.

Em razão destas constatações, pode-se dizer que o nível de independência afeta, 
diretamente, o desempenho de uma ISA, conforme descreve a literatura e, indiretamente, o nível de transparência fiscal de um país. Uma instituição independente e atuante estimula os gestores públicos na adoção de práticas relacionadas com a transparência fiscal.

Entretanto, destaca-se que, em sete países, apesar do nível de independência da ISA ser considerado bom, estes países tinham baixos níveis de transparência fiscal. Esta constatação não invalida a relação entre o nível de independência e o de transparência fiscal, descrita anteriormente. Ao contrário, serve para afirmar que, além do nível de independência de uma ISA, o nível de transparência fiscal de um país é impactado por outras variáveis.

Percebe-se, desta forma, que o presente artigo atingiu satisfatoriamente seu objetivo identificando a possível relação entre o nível de independência de uma ISA e o nível de transparência de um país. Porém, a principal limitação da pesquisa foi o uso de apenas variáveis relacionadas com a independência de uma ISA. No mundo real, a adoção de práticas relativas à transparência fiscal pode ocorrer por influência ou imposição de outros mecanismos ou de outras instituições, não relacionados com as atividades de auditoria pública. Entretanto, esta limitação não prejudica os achados desta pesquisa, restringindo, apenas, estes achados às condições utilizadas para as suas descobertas.

Em futuras pesquisas, sugere-se a exploração de outras variáveis relacionadas com o nível de independência de uma ISA, visando analisar a identificação de novas relações, bem como, a existência de mudanças de comportamento das variáveis, na relação demonstrada neste trabalho.

\section{REFERÊNCIAS}

ARAGÓN, A. G. de Case study: societal perceptions of the Superior Audit Office of Mexico. International Journal of Government Auditing, v. 36, n. 2, p. 15-17, abr. 2009.

BLUME, L.; VOIGT, S. Supreme audit institutions: supremely superfluous? A cross country assessment. ICER Working Paper, v. 3, p. 1-30, mar. 2007.

BRASIL. Constituição da República Federativa do Brasil de 1988. Diário Oficial da União. Brasília: DF. Disponível em: <http://www.planalto.gov.br/ccivil_03/Constituicao/_Constitui çaoCompilado.htm>. Acesso em: 15 mar. 2010.

CLARK, C.; MARTINIS, M.; KRAMBIA-KAPARDIS, M. Audit quality attributes of European Union supreme audit institutions. European Business Review, v. 19, n. 1, p. 40-71, 2007. http://dx.doi.org/10.1108/09555340710714144

DYE, K. M.; STAPENHURST, R. Pillars of integrity: the importance of supreme audit institutions in curbing corruption. Washington: The Economic Development Institute of the World Bank, 1998.

FUNDO MONETÁRIO INTERNACIONAL. Código de boas práticas para a transparência nas políticas monetária e financeira: declaração de princípios. 1999. Disponível em: <http://www.imf.org/external/np/mae/mft/code/por/code2p.pdf >. Acesso em: 10 de mar. 2010.

FUNDO MONETÁRIO INTERNACIONAL. Manual revisto de transparência fiscal. 2001. Disponível em: <http://www.imf.org/external/np/fad/trans/por/manualp.pdf>. Acesso em: 15 jun. 2008.

INTERNATIONAL BUDGET PARTNERSHIP. About the Open Budget Initiative. Disponível em: 〈http://www.openbudgetindex.org/index.cfm?fa=about>. Acesso em: 15 jan. 2010.

GOOLSARRAN, S. A. The evolving role of supreme audit institutions. Journal of 
Government Financial Management, $\quad$ v. $\quad 56, \quad$ n. $\quad 3, \quad$ p. $\quad 28-32,2007$. http://dx.doi.org/10.1007/s10669-004-4800-2

INTOSAI. Declaração de Lima sobre Diretrizes para Preceitos de Auditoria. 1977. Disponível em: <http://portal2.tcu.gov.br/portal/page/portal/TCU/relacoes_institucionais/relacoes_interna cionais/organizacoes_internacionais/DECLARAÇÃO_DE_LIMA_PORT_0.pdf>. Acesso em: 05 jan. 2010.

KOPITS, G.; CRAIG, J. Transparency in government operations. IMF - Occasional Paper, v. 158, p. 1-42, jan. 1998.

LEEUWEN, S. V. Auditing international environmental agreements: the role of supreme audit institutions. The Environmentalist, v. 24, p. 93-99, 2004.

MAROCO, J. Análise estatística - com utilização do SPSS. 3. ed. Lisboa: Edições Sílabo, 2007.

MORIN, D. Welcome to the court. European Group of Public Administration, Madrid, Spain, p. 1-26, set. 2007.

NIKODEM, A. Constitutional regulation of supreme audit institutions in Central Europe in a comparative perspective. Managerial Law, v. 46, n. 6, p. 32-52, 2004. http://dx.doi.org/10.1108/03090550410771044

OCDE. OECD best practices for budget transparency. 2002. Disponível em: <http://www. oecd.org/dataoecd/33/13/1905258.pdf>. Acesso em: 02 fev. 2010.

PIOVESAN, A.; TEMPORINI, E. R. Pesquisa exploratória: procedimento metodológico para o estudo de fatores humanos no campo da saúde pública. Revista Saúde Pública, v. 29, n. 4, p. 318-325, 1995. http://dx.doi.org/10.1590/S0034-89101995000400010

PREMCHAND, A. Fiscal transparency and accountability: idea and reality. In: UNITED NATIONS. Globalization and new challenges of public finance: financial management, transparency and accountability. New York: United Nations, 2002. p. 129-143

SANDBERG, B.; LARSSON, K. The role of auditing in performance improvement in Sweden. In: OECD. Performance auditing and the modernisation of government. Paris: Puma, 1996. p. 195-198

SANTISO, C. Improving fiscal governance and curbing corruption: how relevant are autonomous audit agencies? International Public Management Review, v. 7, n. 2, p. 97$108,2006$.

SUZUKI, Y. Basic structure of government auditing by a supreme audit institution. Government Auditing Review, v. 11, p. 39-53, mar. 2004.

WORLD BANK. Supporting and Strengthening Supreme Audit Institutions: A World Bank Strategy. 7 out. 2004. Disponível em: <http://siteresources.worldbank.org/EXTFINAN CIALMGMT/Resources/313217-1196225463975/4440996-1196226228826/WB-Strategy-Su pport-Strength-SAIs.pdf>. Acesso em: 15 mar. 2010.

ZYL, A. V.; VIVEK, R.; RENZIO, P. Responding to challenges of supreme audit institutions: Can legislatures and civil society help? Bergen: Chr. Michelsen Institute, 2009. 